\title{
Effect of base-acid properties of the mixtures of water with methanol on the solution enthalpy of selected cyclic ethers in this mixture at $298.15 \mathrm{~K}$
}

\author{
Małgorzata Jóźwiak • Agnieszka Warczakowska
}

Received: 7 November 2014/ Accepted: 12 February 2015/Published online: 27 March 2015

(C) The Author(s) 2015. This article is published with open access at Springerlink.com

\begin{abstract}
The enthalpies of solution of cyclic ethers: 1,4dioxane, 12-crown-4 and 18-crown-6 in the mixture of water and methanol have been measured within the whole mole fraction range at $T=298.15 \mathrm{~K}$. Based on the obtained data, the effect of base-acid properties of watermethanol mixtures on the solution enthalpy of cyclic ethers in these mixtures has been analyzed. The solution enthalpy of cyclic ethers depends on acid properties of watermethanol mixtures in the range of high and medium water contents in the mixture. Based on the analysis performed, it can be assumed that in the mixtures of high methanol contents, cyclic ether molecules are preferentially solvated by water molecules.
\end{abstract}

Keywords Cyclic ethers - Water-methanol mixtures · Base-acid properties · Enthalpy of solution

\section{Introduction}

Cyclic ethers [the general formula: $\left(-\mathrm{CH}_{2} \mathrm{CH}_{2} \mathrm{O}-\right)_{n}$ ] especially crown ethers are very interesting group of compounds. Due to their hydrophilic-hydrophobic properties, they are widely used. They can form complexes with cations [1, 2] and small organic molecules [3], and for this reason, they are used in the construction of models of ionic canals [4, 5] and as sensors in ion-selective electrodes $[4,6]$. Crown ethers are known as catalysts in organic synthesis [7-10] and in the nucleophilic substitution [11].

M. Jóźwiak $(\bowtie) \cdot$ A. Warczakowska

Department of Physical Chemistry, Faculty of Chemistry, University of Lodz, Pomorska 165, 90-236 Lodz, Poland

e-mail: mjozwiak@uni.lodz.pl
Especially, due to the use of cyclic ether in organic synthesis, it is necessary to know the effect of properties of the organic solvents or mixed aqueous-organic solvent on the solvation process of cyclic ethers. It is known that the solvation process has a very important role in the course of chemical reactions.

Many papers have dealt with the effect of the properties of pure [7, 11-15] and mixed solvents on physical and chemical processes [16, 17]. The effects of solvent energetic and structural properties [18-20], solvation capabilities [21-27], and acid-base properties of pure and mixed solvents on chemical changes have been reported [28-31]. One of the methods in the investigation of the solvation is the study of the enthalpy of dissolution of the solute.

We continue our study [32-38] on the effect of the acidbase properties of the mixed solvent on the solution enthalpy of cyclic ethers in the mixed solvent. In this paper, we present our observations on the effects of acid-base properties of mixtures of water $(W)$ with methanol $(\mathrm{MeOH})$ on the solution enthalpy of: 1,4-dioxane, 12-crown-4 (12C4), 15-crown-5 (15C5) and 18-crown-6 (18C6).

\section{Experimental}

1,4-Dioxane (Aldrich, 99+\%), “purum” 12-crown-4 (Fluka, $\geq 98 \%$ ), "purum" 18-crown-6 (Fluka, $\geq 99 \%$ ) were used as received.

Methanol (Chempur $>99.8 \%$ ) was purified and dried according to the procedures described in the literature [39] and distilled.

$\mathrm{N}, \mathrm{N}$-dimethylformamide (Aldrich, anhydrous, $99.8 \%$ ) was purified and dried according to the procedures described in the literature $[40,41]$. To prepare the aqueous solutions, doubly distilled water was used. 
The enthalpy of solution of cyclic ethers in the watermethanol $(W+\mathrm{MeOH})$ mixtures was performed at (298.15 \pm 0.01$) \mathrm{K}$ using an "isoperibol"-type calorimeter as described in the literature [42]. The calorimeter was verified on the basis of the standard enthalpy of solution of urea and $\mathrm{KCl}$ (Calorimetric standard US, NBS) in water at $(298.15 \pm 0.01) \mathrm{K}[43,44]$ as was described in our recent publication [45]. The value of solution enthalpy in water obtained by us from seven measurements for urea was $(15.31 \pm 0.06) \mathrm{kJ} \mathrm{mol}^{-1}$ (literature data 15.31 [46], 15.28 [47] and $15.30 \mathrm{~kJ} \mathrm{~mol}^{-1}$ [48]) and for $\mathrm{KCl}$ was (17.55 \pm $0.05) \mathrm{kJ} \mathrm{mol}^{-1}$ (literature data $17.58 \mathrm{~kJ} \mathrm{~mol}^{-1}[43,44]$ ).

The concentration of cyclic ethers in the mixtures was (from 0.00102 to 0.00225 ) $\mathrm{mol} \mathrm{kg}^{-1}$ (the mole per kilogram of solvent). Six to eight independent measurements were performed for each investigation systems. The uncertainties in the measured enthalpies did not exceed $\pm 0.5 \%$ of the measured value. No concentration dependence (outside the error limits) of the measured enthalpies of solution was observed within the examined range of cyclic ethers content. For this reason, the standard solution enthalpy $\Delta_{\text {sol }} H^{\circ}$ was calculated as a mean value of the measured enthalpies (Table 1).

Table 1 Standard enthalpy of solution of 1,4-dioxane, 12C4 and $18 \mathrm{C} 6$ in the mixture $W+\mathrm{MeOH}$ at $298.15 \mathrm{~K}$

\begin{tabular}{|c|c|c|c|}
\hline \multirow[t]{2}{*}{$x_{\mathrm{w}}$} & \multicolumn{3}{|l|}{$\Delta_{\mathrm{sol}} H^{\mathrm{o}} / \mathrm{kJ} \mathrm{mol}^{-1}$} \\
\hline & 1,4-dioxane & $12 \mathrm{C} 4$ & $18 \mathrm{C} 6$ \\
\hline 0.00 & $4.77 \pm 0.03$ & $0.50 \pm 0.04$ & $34.64 \pm 0.06$ \\
\hline 0.10 & $4.24 \pm 0.06$ & $-1.06 \pm 0.03$ & $28.32 \pm 0.07$ \\
\hline 0.20 & $3.70 \pm 0.05$ & $-2.55 \pm 0.03$ & $22.74 \pm 0.04$ \\
\hline 0.30 & $3.21 \pm 0.04$ & $-3.89 \pm 0.02$ & $17.74 \pm 0.05$ \\
\hline 0.40 & $2.73 \pm 0.06$ & $-5.10 \pm 0.06$ & $14.00 \pm 0.06$ \\
\hline 0.50 & $2.40 \pm 0.04$ & $-6.23 \pm 0.05$ & $11.16 \pm 0.02$ \\
\hline 0.60 & $2.08 \pm 0.05$ & $-7.44 \pm 0.06$ & $8.70 \pm 0.04$ \\
\hline 0.70 & $1.67 \pm 0.05$ & $-9.30 \pm 0.04$ & $6.36 \pm 0.05$ \\
\hline 0.80 & $0.29 \pm 0.02$ & $-12.61 \pm 0.03$ & $1.10 \pm 0.06$ \\
\hline 0.90 & $-3.12 \pm 0.03$ & $-18.80 \pm 0.06$ & $-8.10 \pm 0.06$ \\
\hline 0.92 & $-4.12 \pm 0.06$ & $-20.43 \pm 0.05$ & $-10.75 \pm 0.04$ \\
\hline 0.94 & $-5.28 \pm 0.04$ & $-22.33 \pm 0.06$ & $-13.33 \pm 0.06$ \\
\hline 0.96 & $-6.57 \pm 0.05$ & $-24.36 \pm 0.04$ & $-15.95 \pm 0.05$ \\
\hline 0.98 & $-8.08 \pm 0.05$ & $-26.53 \pm 0.06$ & $-18.69 \pm 0.05$ \\
\hline 1.00 & $-9.64 \pm 0.05$ & $-28.98 \pm 0.05$ & $-21.58 \pm 0.06$ \\
\hline 1.00 & $-9.70 \pm 0.02^{\mathrm{a}}$ & $-28.95 \pm 0.05^{\mathrm{b}}$ & $-21.54 \pm 0.05^{\mathrm{b}}$ \\
\hline
\end{tabular}

$x_{\mathrm{w}}$ is the mole fraction of water in the mixed solvent

${ }^{a}$ Ref. [49]

${ }^{b}$ Ref. [50]

\section{Results and discussion}

Figure 1 shows the transfer enthalpy of cyclic ethers $\left(\Delta_{\mathrm{tr}} H^{\mathrm{o}}\right)$ from $W$ to the $W+\mathrm{MeOH}$ mixture (Eq. 1) as a function of water mole fraction in the mixture $x_{\mathrm{w}}$.

$\Delta_{\mathrm{tr}} H^{\mathrm{o}}(W+\mathrm{MeOH})=\Delta_{\mathrm{sol}} H^{\mathrm{o}}(W+\mathrm{MeOH})-\Delta_{\mathrm{sol}} H^{\mathrm{o}}(W)$

where $\Delta_{\mathrm{tr}} H^{\mathrm{o}}(W+\mathrm{MeOH})$ is the transfer enthalpy of cyclic ethers from water to the mixture $W+\mathrm{MeOH}, \Delta_{\text {sol }} H^{\circ}$ $(W+\mathrm{MeOH})$ is the solution enthalpy of cyclic ethers in the mixture $W+\mathrm{MeOH}$, and $\Delta_{\text {sol }} H^{\mathrm{o}}(W)$ is the solution enthalpy of cyclic ethers in $W$.

In order to compare the data obtained, the transfer enthalpy of 15 -crown-5 ether (15C5) has been added [51]. As is seen in this figure, the shapes of the transfer enthalpy curves of the cyclic ethers investigated are similar.

In the range of low water content in the mixtures, we can observe decrease in the transfer enthalpy of cyclic ethers with the increasing concentration of water in the mixtures. With the increase in the cyclic ring, the variability of the transfer enthalpy curves as a function of $x_{\mathrm{w}}$ becomes more expressive. This is connected with the structure of the

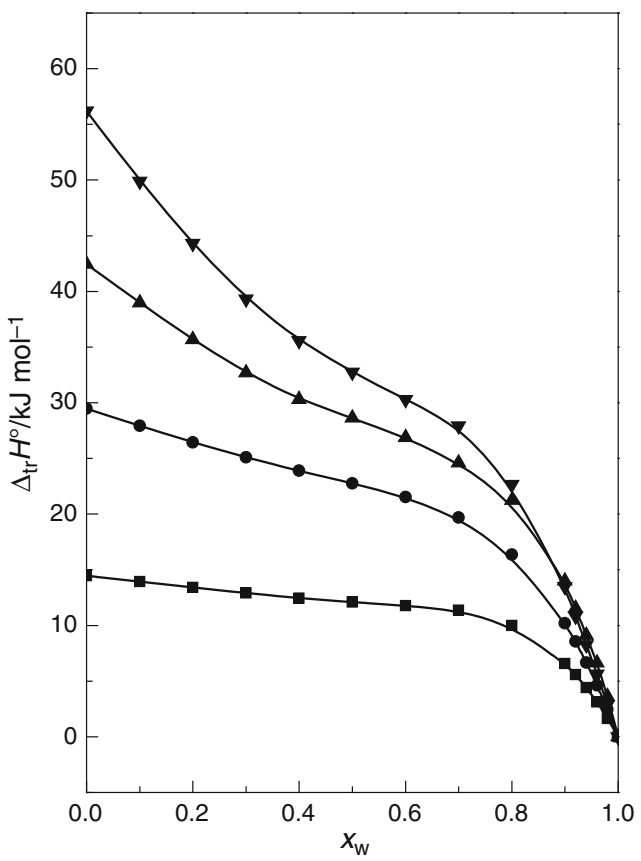

Fig. 1 Transfer enthalpy of cyclic ethers: 1,4-dioxane (filled square), 12C4 (filled circle), 15C5 (filled triangle; data calculated using the values of solution enthalpy of 15C5 (from Ref. [51]) and 18C6 (filled inverted triangle) from water to the mixtures $W+\mathrm{MeOH}$ as a function of water mole fraction $\left(x_{\mathrm{w}}\right)$ at $298.15 \mathrm{~K}$ 
mixed solvent and interactions of cyclic ether molecules with molecules, which are components of the mixture.

Based on the mass spectroscopic analysis of clusters in alcohol-water mixtures, Wakisaka et al. [52] suggest that the preferential solvation of a hydrophobic substance by alcohol molecules in the mixture of methanol and water is promoted by the alcohol self-aggregation in the solution within the region of medium and high methanol contents.

In our previous publication [51], we have shown also that the molecules $15 \mathrm{C} 5$ are preferentially solvated by either water molecules or by methanol molecules, depending on the water content of the mixture. On the other hand, the presence of $-\mathrm{CH}_{3}$ group in the methanol molecule can cause that some contribution characteristics of hydrophobic groups, especially within the water-rich range, will also be made to the properties of this compound [53].

In our previous publication [54, 55], we have shown that the enthalpic effect of hydrophobic hydration of methanol is much smaller than the corresponding effect for the cyclic ethers. The enthalpic effect of hydrophobic hydration of cyclic ethers increases with increasing cyclic ether ring. The process of hydrophobic hydration of cyclic ethers is reflected in Fig. 1 in the area of high water content. There is a sharp decrease in the enthalpy of transfer of cyclic ethers.

We analyzed the shapes of the curves acid-base parameters of a mixture $W+\mathrm{MeOH}$ and dissolution enthalpy curves of cyclic ethers in the mixture. Lewis acidity expressed by the standardized Dimroth-Reichardt's parameter $E_{\mathrm{T}}^{\mathrm{N}}$ and basicity of Kamlet-Taft $B_{\mathrm{KT}}$ for the $W+\mathrm{MeOH}$ mixtures [56] (Fig. 2).

The molecules of cyclic ethers contain oxygen atoms with free electron pairs. This fact causes that the cyclic ethers can be regarded as centers of Lewis basicity. For this reason, the analysis is used with Lewis's acidity $\left(E_{\mathrm{T}}^{\mathrm{N}}\right)$. Therefore, it was decided to present the enthalpy of solution as a function of $E_{\mathrm{T}}^{\mathrm{N}}$ (Eq. 2).

$\Delta_{\text {sol }} H^{\mathrm{o}}=Q_{\mathrm{o}}+a \cdot E_{\mathrm{T}}^{\mathrm{N}}$

where $Q_{\mathrm{o}}$ is the value of the given property in the absence of the solvent effect, while $a$ is the contribution of acidic properties to the variation of enthalpy of solution. The parameters of the obtained relationship are given in Table 2 (columns a). The functions $\Delta_{\text {sol }} H^{\circ}$ $(W+\mathrm{MeOH})=f\left(E_{\mathrm{T}}^{\mathrm{N}}\right)$ for 1,4-dioxane, 12C4, 15C5 [51] and 18C6 are shown in Fig. 3.

It was observed that parameter $a$ linearly increased with the increase in the number of oxygen atoms $n_{-\mathrm{O}_{-}}$in the molecules of cyclic ethers (Eq. 3). Standard deviations are given in parentheses.

$a=26.38( \pm 14.95)-38.81( \pm 3.32) \cdot n_{-\mathrm{O}-}$

$r^{2}=0.98555, \quad S D=9.8293$

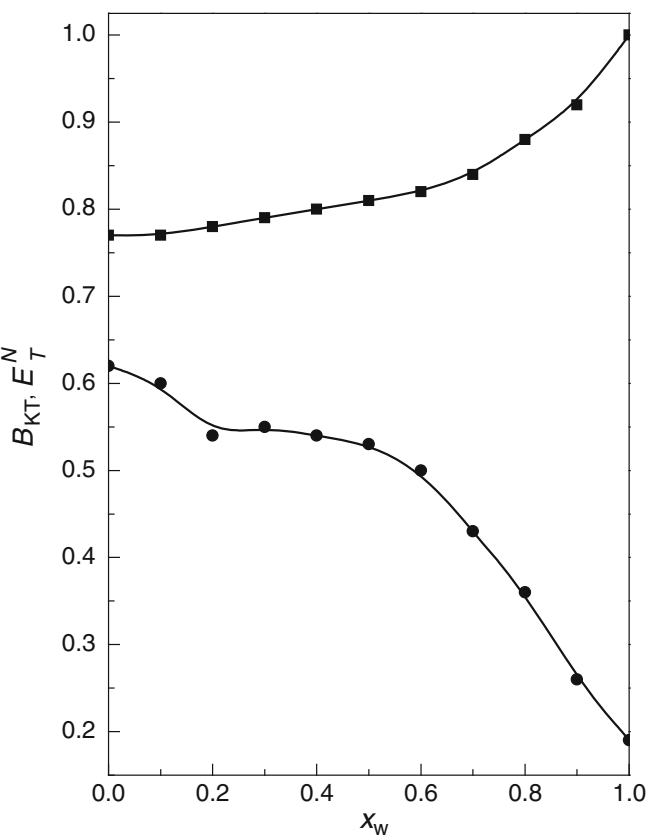

Fig. 2 Base (filled circle)-acid (filled square) properties of $W+\mathrm{MeOH}$ mixtures at $298.15 \mathrm{~K}$ (data from Ref. [56])

It was also observed that the regression coefficient $\left(r^{2}\right)$ is the highest for $12 \mathrm{C} 4$ and for 1,4-dioxane, and for $15 \mathrm{C} 5$ and $18 \mathrm{C} 6 r^{2}$, it is much lower. This means that for the greater cyclic ether ring particularly, the dependence (2) is more disturbed. The solution enthalpy of cyclic ethers was calculated using Eq. 2 and the parameters given in Table 2. The results obtained are shown in Fig. 4a. As is seen, the courses of function $\Delta_{\mathrm{sol}} H^{\mathrm{o}}=f\left(x_{\mathrm{w}}\right)$ calculated with the use of Eq. 2 and that obtained by way of experiment clearly differ in the case of $15 \mathrm{C} 5$ and $18 \mathrm{C} 6$. This is probably due to the preferential solvation of $15 \mathrm{C} 5$ and $18 \mathrm{C} 6$ molecules by methanol molecules or water molecules. One can not exclude the formation of hydrogen bonds $15 \mathrm{C} 5$ and $18 \mathrm{C} 6$ molecules with molecules of methanol in the mixtures with high methanol content.

We have made calculations again omitting data of solution enthalpy of cyclic ethers and $E_{\mathrm{T}}^{\mathrm{N}}$ for the mixtures of high concentration methanol. We skipped the mixture: $x_{\mathrm{w}}=0, x_{\mathrm{w}}=0.1$ and $x_{\mathrm{w}}=0.2$. The results obtained are given in Table 2 (columns b) and in Fig. 4b. As seen in Table 2, regression coefficient $r^{2}$ has increased significantly and the curves shape is well matched to the curve obtained experimentally in the medium and high water content in the mixed solvent.

Moreover, as previously coefficient $a$ increases linearly with the increase in the cyclic ring (Eq. 4) but with a much higher regression coefficient $\left(r^{2}\right)$ and much lower standard deviation $(\mathrm{SD})$. 


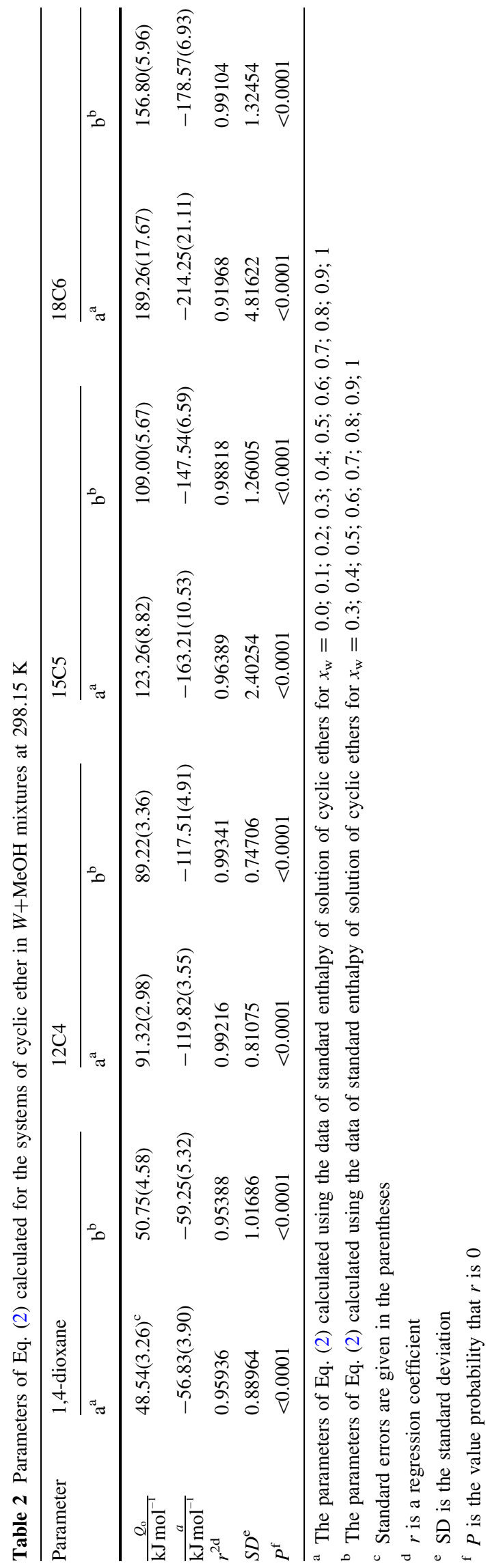

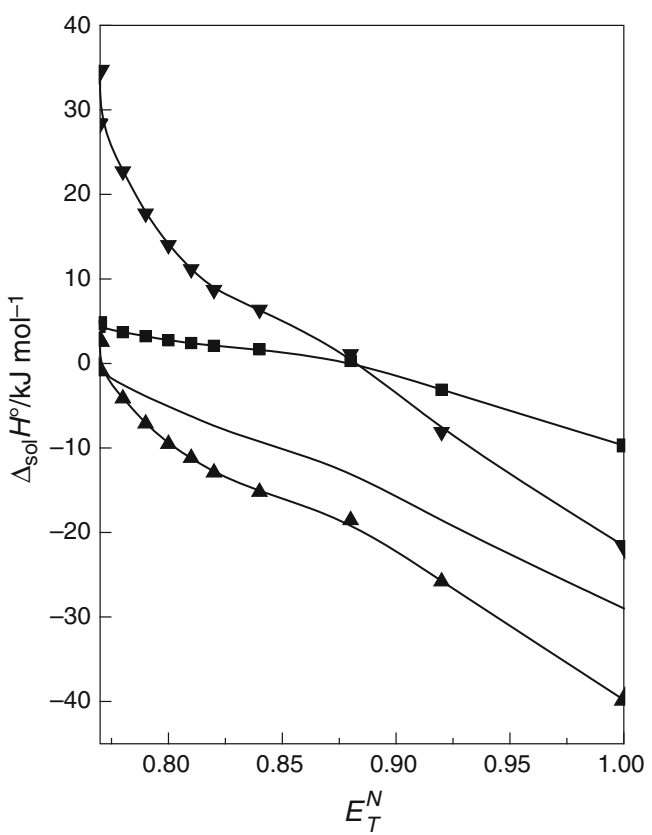

Fig. 3 Standard enthalpy of solution 1,4-dioxane (filled square), 12C4 (filled circle), 15C5 (filled triangle) [51] and 18C6 (filled inverted triangle) as a function of acid properties of $W+\mathrm{MeOH}$ mixture

$a=0.79( \pm 1.39)-29.77( \pm 0.31) \cdot n_{-\mathrm{O}-}$
$r^{2}=0.99978, \quad S D=0.91527$

As is seen in Fig. $4 b$, the conformability of the courses of these functions for cyclic ethers has been considerably improved, which indicates that the acidic properties of the mixture play a significant part in the interactions between the molecules of cyclic ethers (particularly 15C5 and 18C6) and the mixture components in the range of medium and high water content. One can still observe considerable deviations of the courses of function $\Delta_{\mathrm{sol}} H^{\mathrm{o}}=f\left(x_{\mathrm{w}}\right)$ calculated with the use of Eq. 2 and that obtained by the experimental way in the case of $15 \mathrm{C} 5$ and $18 \mathrm{C} 6$ within the range of high methanol content.

As shown in Table 2, the value of $Q_{\mathrm{o}}$ is positive in all cases, which means that the process of dissolution in the absence of solvent effects is endothermic. A negative value of the parameter $a$ (the contribution of acidic properties to the variation of solution enthalpy) shows a very significant influence of solvent effects (in this case, the acidic properties of the mixture $W+\mathrm{MeOH}$ ) on the solution process of the cyclic ethers.

Based on the analysis performed, it can be assumed that in the mixtures of high methanol contents, cyclic ether molecules are preferentially solvated by water molecules. We can assume as before [51] that at $x_{\mathrm{w}} \leq 0.3$, the methanol molecules are strongly associated and the $\mathrm{MeOH}-\mathrm{MeOH}$ interactions are stronger than those of 
Fig. 4 Standard solution enthalpy of 1,4-dioxane (filled square), $12 \mathrm{C} 4$ (filled circle), 15C5 (filled triangle; data from Ref. [51]) and 18C6 (filled inverted triangle) in $W+\mathrm{MeOH}$ mixture at $T=298.15 \mathrm{~K}$ as a function of $x_{\mathrm{w}}$ : experimental data (solid line) and data calculated using the Eq. 2 (doted line)
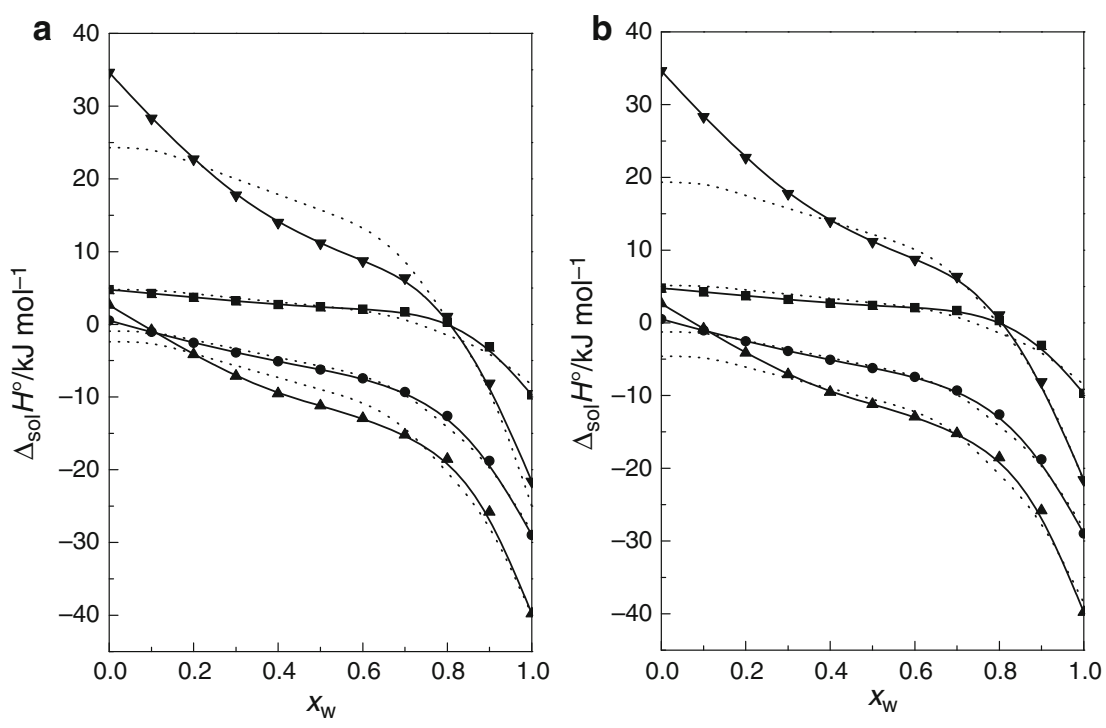

cyclic ether molecules with methanol; therefore, cyclic ether molecules react with water. This may be the reason that Eq. 2 is not fulfilled within the whole concentration range of the mixed solvent.

Open Access This article is distributed under the terms of the Creative Commons Attribution License which permits any use, distribution, and reproduction in any medium, provided the original author(s) and the source are credited.

\section{References}

1. Izatt RM, Bradshaw JS, Nielsen SA, Lamb JD, Christensen JJ. Thermodynamic and kinetic data for cation-macrocycle interaction. Chem Rev. 1985;85:271-339.

2. Izatt RM, Pawlak K, Bradshaw JS, Bruening RL. Thermodynamic and kinetic data for macrocycle interaction with cations and anions. Chem Rev. 1991;91:1721-2085.

3. Izatt RM, Bradshaw JS, Pawlak K, Bruening RL, Tarbet BJ. Thermodynamic and kinetic data for macrocycle interaction with neutral molecules. Chem Rev. 1992;92:1261-354.

4. Gokel GW, Leevy WM, Weber ME. Crown ethers: sensors for ions and molecular scaffolds for materials and biological models. Chem Rev. 2004;104:2723-50.

5. Tsukube H, Yamada T, Shinoda S. Crown ether strategy toward chemical activation of biological protein functions. J Heterocycl Chem. 2001;38:1401-8.

6. Moriarty RM, Rao MSC, Tuladhar SM, D'Silva C, Williams G, Gilardi R. Crown ether ionophores. Construction of neutral carrier ion-selective electrodes. J Am Chem Soc. 1993;115:1194-6.

7. Chen HCh, Chen SH. Diffusion of crown ethers in alcohols. J Phys Chem. 1984;88:5118-21.

8. Linghu X, Bausch CC, Johnson JS. Mechanism and scope of the cyanide-catalyzed cross silyl benzoin reaction. J Am Chem Soc. 2005; 127:1833-40.

9. Liu YK, Yue L, Li R, Li BJ, Chen YCh, Wu Y, Ding LS. Unexpected ring-opening reactions of aziridines with aldehydes catalyzed by nucleophilic carbenes under aerobic conditions. Org Lett. 2006;8:1521-4.
10. France S, Wack H, Taggi AE, Hafez AM, Wagerle TR, Shah MH, Dusich CL, Lectka T. Catalytic, asymmetric $\alpha$-chlorination of acid halides. J Am Chem Soc. 2004;126:4245-55.

11. Katritzky AR, Rees ChW, Scriven EFV. Comprehensive heterocyclic chemistry II. A review of the literature 1982-1995, G. R. Newkome, Pergamon, FL, USA. 1996;9:1-1146.

12. Abraham MH, Grellier PL, Abboud JLM, Doherty RM, Taft RW. Solvent effects in organic chemistry-recent developments. Can J Chem. 1988;66:2673-96.

13. Szpakowska M, Nagy OB. Application of the competitive preferential solvation theory to facilitated ion transport through binary liquid membranes. J Phys Chem. 1989;93:3851-4.

14. Katritzky AR, Fara DC, Yang H, Tämm K. Quantitative measures of solvent polarity. Chem Rev. 2004;104:175-98.

15. Castronuovo G, Niccoli M. Solvent effects on the complexation of 1-alkanols by parent and modified cyclodextrins. Calorimetric studies at $298 \mathrm{~K}$. J Therm Anal Calorim. 2011;103:641-6.

16. Heter G, Marcus Y, Waghorne WE. Enthalpies and entropies of transfer of electrolytes and ions form water to mixed aqueous organic solvents. Chem Rev. 2002;102:2773-836.

17. Marcus Y. Gibbs energies of transfer of anions from water to mixed aqueous organic solvents. Chem Rev. 2007;107:3880-97.

18. Ohtaki H. An attempt to parameterize the structuredness of solvents. J Solut Chem. 1992;21:39-47.

19. Lynden-Bell RM, Giovambattista N, Debenedetti PG, HeadGordon T, Rossky PJ. Hydrogen bond strength and network structure effects on hydration of non-polar molecules. PCCP. 2011;13:2748-57.

20. Nunes N, Reis M, Moreira L, Elvas-Leitão R. Solution enthalpies of 1,4-dioxane: study of solvent effects through quantitative structureproperty relationships. Thermochim Acta. 2013;574:85-7.

21. Marcus Y. The effectivity of solvents as electron pair donors. J Solut Chem. 1984;13:599-624.

22. Marcus Y. Linear solvation energy relationships. Correlation and prediction of the distribution of organic solutes between water and immiscible organic solvents. J Phys Chem. 1991;95: 8886-91.

23. Barannikov VP, Guseynov SS, Parfenyuk EV, Vyugin AI. Correlation of enthalpic and volume characteristics of 15-crown-5 in solution with molecular parameters and physical properties of solvents. Thermochim Acta. 1999;326:75-81. 
24. Obrzud M, Rospenk M, Koll A. Self-association of $N, N$-dialkylthiourea derivatives in non-polar solvents. J Mol Struct. 2012;1018:54-63.

25. Barannikov VP, Guseynov SS, Vyugin AI. Enthalpies of solvation of ethylene oxide oligomers $\mathrm{CH}_{3} \mathrm{O}\left(\mathrm{CH}_{2} \mathrm{CH}_{2} \mathrm{O}\right)_{\mathrm{n}} \mathrm{CH}_{3}(\mathrm{n}=1$ to 4 ) in different H-bonding solvents: methanol, chloroform, and water. Group contribution method as applied to the polar oligomers. J Chem Thermodyn. 2011;43:1928-35.

26. Li Y, Huszthy P, Móczár I, Szemenyei B, Kunsági-Máté S. Solvent effect on the complex formation of a crown ether derivative with sodium and potassium ions. Thermodynamic background of selectivity. Chem Phys Lett. 2013;556:94-7.

27. Usacheva TR, Sharnin VA. Effect of solvation on the complexation of 18-crown-6 with amino acids in aqueous-organic media. Russ J Gen Chem. 2014;84:911-7.

28. Krygowski TM, Fawcett WR. Complementary Lewis acid-base description of solvent effects. I. Ion-ion and ion-dipole interactions. J Am Chem Soc. 1975;97:2143-8.

29. Fawcett WR, Krygowski TM. Complementary Lewis acid-base description of solvent effects. II. Dipole-dipole interactions. Aust J Chem. 1975;28:2115-24.

30. Fawcett WR, Krygowski TM. A characteristic vector analysis of solvent effects for thermodynamic data. Can J Chem. 1976;54:3283-92.

31. Wrona PK, Krygowski TM, Galus Z. Correlation between empirical Lewis acid-base solvent parameters of ion solvation. Part II. Acidity parameters of cations and basicity parameters of anions. J Phys Org Chem. 1991;4:439-48.

32. Jóźwiak M, Piekarski H. Thermochemical behaviour of crown ethers aqueous organic solvents. Part IV. Propanol and acetonitrile with water mixtures. J Thermal Anal Calorim. 2002;69:291-300.

33. Jóźwiak M. Effect of base-acid properties of the mixture of water with propan-1-ol on the solution enthalpy of cyclic ethers in this mixture at $\mathrm{T}=298.15 \mathrm{~K}$. J Chem Eng Data. 2011;56:4710-4.

34. Jóźwiak M. The effect of properties of water-organic solvent mixtures on the solvation enthalpy of 12-crown-4, 15-crown-5, 18-crown-6 and benzo-15-crown-5 ethers at $298.15 \mathrm{~K}$. Thermochim Acta. 2004;417:31-41.

35. Jóźwiak M. Thermochemical behaviour of crown ethers in the mixtures of water with organic solvents. Part IX. Effect of baseacid properties of $(1-\mathrm{x}) \mathrm{AN}+\mathrm{xH}_{2} \mathrm{O}$ on the solution enthalpy of cyclic ethers in this mixed solvent at $\mathrm{T}=298.15 \mathrm{~K}$. J Chem Thermodyn. 2009;41:522-4.

36. Jóźwiak M, Bald A, Jóźwiak A. Complex formation of crown ethers and cations in water-organic solvent mixtures. Part XI. Effects of the preferential solvation of benzo-15-crown-5 and base-acid properties of the mixture on the thermodynamic function of complex formation of benzo-15-crown-5 with $\mathrm{Na}^{+}$in water-propan-1-ol mixtures at $298.15 \mathrm{~K}$. J Solut Chem. 2009;38:1283-94.

37. Jóźwiak M, Madej L. Complex formation of crown ethers and cations in water-organic solvent mixtures. Part XII. Effect of the base-acid properties of the mixture on the thermodynamic function of complex formation of benzo-15-crown-5 with $\mathrm{Na}^{+}$in water-methanol mixtures at $298.15 \mathrm{~K}$. J Solut Chem. 2009;38:1635-47.

38. Jóźwiak M. The effect of carbonyl carbon atom replacement in acetone molecule (ACN) by sulphur atom (DMSO) Part III. Effect of base-acid properties of the mixtures of water with acetone or dimethyl sulfoxide on the solution enthalpy of cyclic ethers in mixed solvent. J Therm Anal Calorim. 2010;101:1039-45.
39. Maryott AA. Electric polarization and association in solution. III. The dipole moments of some alcohols in very dilute benzene solutions. J Am Chem Soc. 1941;63:3079-83.

40. Chan SC, Valleau JP. Ultrasonic study of hydrochloric acid association in $\mathrm{N}, \mathrm{N}$-dimethylformamide. Can J Chem. 1968;46:853-8.

41. Schmulbach CD, Drago RS. Molecular addition compounds of iodine. III. An infrared investigation of the interaction between dimethylacetamide and iodine. J Am Chem Soc. 1960;82:4484-7.

42. Piekarski H, Waliszewski D. Hydration effect on urea-non-electrolyte enthalpic pair interaction coefficients. Dissolution enthalpies of urea in aqueous solution of alkoxyethanols at 298.15 K. Thermochim Acta. 1995;258:67-76.

43. Sabbah R, Xu-wu A, Chickos JS, Planas Leitão ML, Roux MV, Torres LA. Reference materials for calorimetry and differential thermal analysis. Thermochim Acta. 1999;331:93-204.

44. Wadsö I, Goldberg RN. Standards in isothermal microcalorimetry (IUPAC Technical Report). Pure Appl Chem. 2001;73:1625-39.

45. Jóźwiak M, Madej-Kiełbik L. Effect of temperature on the process of complex formation crown ether $15 \mathrm{C} 5$ with $\mathrm{Na}^{+}$in the (water + ethanol) mixture at temperatures from (293.15 to 308.15)K. Thermochim Acta. 2014;580:13-9.

46. Pałecz B. The enthalpies of interaction of glycine with some amides and ureas in water at $25^{\circ} \mathrm{C}$. J Solut Chem. 1995;24:537-50.

47. Desnoyers JE, Perron G, Avedikian L, Morel JP. Enthalpies of the urea-tert-butanol-water system at $25{ }^{\circ} \mathrm{C}$. J Solut Chem. 1976;5:631-44.

48. Egan EP Jr, Luff BB. Heat of solution, heat capacity, and density of aqueous urea solutions at $25^{\circ} \mathrm{C}$. J Chem Eng Data. $1966 ; 11: 192-4$.

49. Jóźwiak M. Thermochemical behaviour of crown ethers in the mixtures of water with organic solvents. Part VIII. Hydrophobic hydration and preferential solvation of 1,4-dioxane in $(1-$ x)amide $+\mathrm{H}_{2} \mathrm{O}$ at $\mathrm{T}=298.15 \quad \mathrm{~K}$. J Chem Thermodyn. 2007;39:433-7.

50. Briggner LE, Wadsö I. Some thermodynamic properties of crown ethers in aqueous solution. J Chem Thermodyn. 1990;22:143-8.

51. Jóźwiak M, Madej-Kiełbik L, Piekarski H. Effect of temperature on the solvation of 15-crown-5 ether in water-methanol mixtures. Thermochim Acta. 2012;533:22-7.

52. Wakisaka A, Komatsu S, Usui Y. Solute-solvent and solventsolvent interactions evaluated through clusters isolated from solutions: preferential solvation in water-alcohol mixtures. J Mol Liq. 2001;90:175-84.

53. Tanaka H, Gubbins KE. Structure and thermodynamic properties of water-methanol mixtures: role of the water-water interaction. J Chem Phys. 1992;97:2626-34.

54. Jóźwiak M, Kosiorowska MA. Effect of temperature on the process of hydrophobic hydration. Part I. Hydrophobic hydration of 1,4-dioxane and 12-crown-4 ethers. J Chem Eng Data. 2010;55:2776-80.

55. Jóźwiak M, Kosiorowska MA, Wasiak M. Effect of temperature on the process of hydrophobic hydration. Part II. Hydrophobic hydration of 15-crown-5 and 18-crown-6 ethars. J Chem Eng Data. 2010;55:5138-43.

56. Krygowski TM, Wrona PK, Zielkowska U. Empirical parameters of Lewis acidity and basicity for aqueous binary solvent mixtures. Tetrahedron. 1985;41:4519-27. 